\title{
THE ARABIC LANGUAGE AND CONTEMPORARY EGYPTIAN NATIONAL VALUES: A LEXICAL ANALYSIS
}

\author{
Walter RENNER ${ }^{1)}$ and Kathleen MYAMBO ${ }^{2)}$ \\ 1) Alps-Adria University of Klagenfurt, Austria \\ ${ }^{2)}$ American University in Cairo, Egypt
}

\begin{abstract}
Aiming at compiling a culture specific taxonomy of Arabic values, four Egyptian raters extracted 327 value descriptive nouns from a dictionary of Arabic. These concepts were rated as personal guiding motives by 773 Egyptian students at the American University in Cairo (AUC), 490 of them women. Principal Components Analysis with varimax rotation yielded six factors which explained $29.4 \%$ of the variance: I. Nobility and Compassion, II. Discipline, III. Advancement, IV. SelfActualization, V. Belief and Commitment and VI. Counter-Culture. These factors were named and interpreted by a focus group of seven former or current AUC students. The value dimensions reflect the traditional ethic of Arabic society and focus on community related issues which are characteristic of collectivist societies.
\end{abstract}

Key words: human values, Egypt, lexical approach, culture

Human values are cognitive and emotional abstractions of people's aims, attitudes, and actions. For several years, researchers have focused on finding universal values that were supposed to be common to all cultures. Schwartz (1992), for example, developed the Schwartz Value Survey (SVS) and proposed ten categories of universal values. In addition to the search for universal values, researchers have also explored cultural differences in value orientations that arose from socialization (Hofstede, 1994; SchollSchaaf, 1975; Schwartz, 1994). One of the major findings was that cultures varied consistently in terms of individualist and collectivist values (Hofstede, 1984).

The need to supplement research on universal values with research on culture specific values has been noted recently in several empirical studies that used the "lexical approach". Values were studied by Aavik and Allik (2002) in Estonia, Renner (2003) in Austria and Renner, Peltzer and Phaswana (2003) in an indigenous South African society. Additionally, Cawley, Martin and Johnson (2000) studied virtues and Saucier (2000) examined ideological concepts in the USA. The "lexical approach" is used to study cultural specific aspects of values and value related concepts. This method was originally developed to study human personality traits and was instrumental in establishing the Big

The financial support of the American University in Cairo and the University of Klagenfurt towards this study is hereby gratefully acknowledged. We would also like to acknowledge the expertise offered in translation and transliteration by Dr. David Wilmsen, Director of Arabic and Translation Studies Division, Center for Adult and Continuing Education, American University in Cairo, Cairo, 11511, Egypt. We also thank Ingrid Salem for valuable advice and Margot Vrisk for her efficient processing of the data.

Correspondence concerning this article should be addressed to Walter Renner, Ph.D., Department of Psychology, University of Klagenfurt, Universitätsstrasse 65-67, A-9020 Klagenfurt, Austria (e-mail: walter.renner@uni-klu.ac.at) FAX: ++43/463/2700/1697 
Five personality factors (cf. De Fruyt \& Furnham, 2000). The central assumption in a lexical approach is that important individual differences, in the course of time, became encoded in a people's language. Therefore, such differences can be detected by a review of that society's dictionary, the extraction of an exhaustive list of words that relate to the concepts in question (e.g., traits or values), and the subsequent use of factor analysis in order to reduce the amount of information to a manageable number of dimensions. The present study aimed at applying the lexical approach to the values of Egyptian society.

\section{Characteristics of Arabic Values}

The values of Arab society represent ancient ideals of sedentary people on the one hand and those of nomadic Bedouins on the other. The sedentary population has emphasized being submissive, persevering, tenacious and cunning whereas the Bedouins used to value virtues like being courageous, proud, and aggressive (Ali, 1986; Ali \& AlShakis, 1985, 1989; Almaney, 1981). The Bedouin tradition also encompasses the ideals of hospitality, honor, rivalry, and revenge (Ali \& Al-Shakis, 1985).

The value systems of both, the sedentary and the Bedouin population, have been influenced by the Qu'ran and the Hadith, the teachings of the Prophet Mohammed. Islam emphasizes respecting rules and authorities as well as the family hierarchy which is determined by age and gender (Ali \& Al-Shakis, 1985). Values like being generous, tolerating other people's faults and caring for one's family and the poor are of utmost importance. Religion plays a prominent role in Arabic society (Ali, 1987; Harris \& Moran, 2000; Moracco, 1983; Sidani \& Gardner, 2000). Barakat (1974) and Buchanan (1997) noted that religious and political issues converge in Arab society and religiosity permeates all other aspects of life.

Al Hashimi (1981) criticized Western psychology for not accounting for the spiritual dimension of human life and called for the establishment of "Islamic Psychology" (p. 66). Although the cultural differences between Arabic nations should be noted, about $90 \%$ of Arabs are Muslims (Moracco, 1983) and findings on Arabic values may be generalized cautiously to "Islamic values", as suggested by Al-Hashimi (1981). Moracco (1983) emphasized that to Arabs, their language is of special psychological importance, "for it is the chosen language of the Qu'ran, and it is thought by them to be the ideal language for poetry" (p. 48). Similarly, Joseph (1991) outlined the culturally specific role of rhetoric in Arab speaking countries.

Arabic society is conservative with respect to attitudes toward women. Fulfilling the spouse's expectations, having children and being responsible for family harmony are central. The traditional gender roles imply that women are considered unable to exist independently of men (Abdalla, 1996; Hattar-Pollara, Meleis \& Nagib, 2000). Feeling responsible for the chastity of daughters and sisters is of utmost significance for Arabic men's self-esteem (Patai, 1973).

In the above mentioned respects, Arabic values differ from the mostly "individualist" values of "Western" societies. Arab cultures have been judged to be moderately collectivistic, while Western cultures, for example Germany or the USA are characterized by individualistic ideals (Hofstede 1984, 1994; Triandis, 1995). Patai (1973) has 
emphasized the high cohesion of kin groups and families in the Arab world (cf. Barakat, 1974 and Moracco, 1983). He also outlined the importance of preserving one's "face" and avoiding shame in the case of failure.

In contrast to the traditional Islamic world view which emphasized predestination and promoted a rather passive image of the individual (Ali, 1987; Hajazi, 1979; Moracco, 1983; Patai, 1973), there is a tendency in the contemporary interpretation of Islam to view humans as God's responsible agents in the world (Haddad, 1984; Sidani \& Gardner, 2000). In the contemporary Arab world traditional and Western values co-exist (Ali, 1986; Ali \& Al-Shakis, 1985) and the value systems are undergoing rapid changes (Almaney, 1981; Haddad, 1984). The first steps to modify the traditional gender roles are being reported (Thomas, 2000).

\section{Characteristics of Egyptian Values}

While some researchers have emphasized what Arab countries have in common (Patai, 1973), others have argued that they differ from each other essentially in regard to their value systems (Ali \& Al-Shakis, 1985; Sidani \& Gardner, 2000). With respect to Egypt, it should be noted that Egyptian culture has been significantly influenced by colonial expansion in the $19^{\text {th }}$ and $20^{\text {th }}$ centuries, most notably by the French and British (Hopkins \& Ibrahim, 1997). A review of the literature on Arabic values in the Middle East shows that little research has been done in Egypt.

In the present study we investigated Egyptian values using the lexical approach and factor analysis. The central expectation of the present research was that Egyptian values would reflect the ideals characteristic of Arab countries, of Islam and of collectivist societies as noted above. In addition to the factor analysis, two correlational studies were done. In the first, the Egyptian value dimensions were correlated with the SVS and we expected moderate correlations because the two scales refer to different aspects of human values, that is, cultural versus universal. In the second correlational study, we expected low correlations between Egyptian values and the Big Five personality dimensions as values should be distinct from personality traits.

\section{METHOD}

\section{Participants}

Four Arabic native speakers who were Egyptian and living in Cairo compiled the questionnaire. All were female and ranged in age between 21 and 27 years old. Two held university degrees from universities in Egypt and two were final year students in the psychology degree at the American University in Cairo (AUC). We administered this questionnaire to 773 native speakers of Arabic studying at the American University in Cairo; 490 of them were women and 276 were men; seven participants did not state their gender. The mean age was 19.24 years $(S D=1.8)$. For the purpose of data analysis, participants who had left more than $10 \%$ of the items unanswered were excluded and thus, 745 participants with a mean age of 19.24 years $(S D=1.6)$ remained. This final sample comprised 473 women and 266 men and six participants who did not state their gender.

After the factor analysis of the value ratings was completed, the table of factor loadings was presented to a focus group, comprising seven AUC students or former AUC students who were Egyptian and Muslim. Their age ranged between 19 and 26 years, and all read and spoke both Arabic and English. The task of the 
focus group was to interpret and to give labels to the factors. A second focus group, comprising four further AUC students, ranging in age from 21 to 23 years then reviewed the work of the first focus group.

For exploratory purposes, a small sub-sample of those who completed the values scale also completed the SVS (Schwartz, 1992) and NEO Five-Factor Inventory (NEO-FFI) (Costa \& McCrae, 1992). Forty-one participants (33 women and 8 men, mean age 20.5 years, $S D=1.86$ completed the SVS and these 41 participants plus a further two participants completed the NEO-FFI (a total of 35 women and 8 men, mean age $20.4, S D=1.9$ ).

\section{Compiling the Questionnaire}

The procedure was analogous to the one employed in Austria and South Africa before (cf. Renner, 2003 and Renner et al., 2003). Two bi-lingual research assistants who knew both Arabic and English derived a taxonomy of values terms from the Al-Mawrid Modern Arabic-English dictionary (Baalbaki, 2001). The original list had 707 nouns. The list was revised by a further two research assistants to a list of 446 nouns. This list was used in a pilot study involving 63 students at the American University in Cairo. On the basis of this pilot study and the advice of four linguistic experts of Arabic, the list was reduced to 327 nouns. In the final version of the questionnaire each value term was to be rated on an eleven point Likert type scale ranging from -5 , indicating strong disapproval, through 0 (neutral), to +5 , meaning strong approval. Each concept was rated with respect to its importance as a personal guiding motive.

\section{Further Measures}

The Schwartz Value Survey (SVS, Schwartz, 1992) comprises 57 items on ten oblique dimensions (Conformity, Tradition, Benevolence, Universalism, Self-Enhancement, Stimulation, Hedonism, Achievement, Power and Security). By translating this questionnaire from English to foreign languages, this structure of values was largely confirmed in 61 countries (Schwartz \& Bardi, 2001). In the present study, an Arab version of the SVS was employed (S. H. Schwartz, personal communication, October 2003).

The Big Five dimensions of personality were measured by an Arabic translation of the NEO-FiveFactor Inventory (NEO-FFI) (Costa \& McCrae, 1992).

\section{Statistical Methods}

In order to obtain orthogonal factors, principal component analysis with varimax rotation was employed. As parallel analysis has proven to yield far too many factors which did not meet the requirements by Fürntratt (1969) in a previous study (Renner, 2003), the eigenvalue criterion was used in order to determine the number of factors to be extracted. This criterion resembles Cattell's (1966) Scree-test.

The sample size of 745 used in Principal Components Analysis may appear small in relation to the number of variables according to frequently used conventional criteria for factor analysis. According to recommendations by Guadagnoli and Velicer (1988), however, a sufficiently stable factorial structure can be expected with the current sample size, as long as only factor loadings $>.30$ will be interpreted.

As a basis for correlational analyses, factor scores were computed for the Egyptian value dimensions. For this purpose, the regression method was used. For the SVS and the NEO-FFI, on the other hand, we followed the scoring instructions given by the respective authors. Thus, for each of the SVS and the NEOFFI scales, the statistical means were computed and the respective scale scores were used for further analyses, while for the Egyptian value dimensions, the correlational analyses were based on their factor scores.

When computing coefficients of correlations between the factor scores of the value dimensions and the scales of the SVS, we followed the instructions by Schwartz (1992). In order to account for response sets (i.e. the tendency to value all the concepts high or all the concepts low), partial correlations were computed, controlling for the total score of the SVS.

\section{Focus Groups}

The focus group was chaired by the second author and an Egyptian Senior Research Assistant who had worked with the second author in developing the final values scale. The table of factor loadings was presented to the group members and they were asked to give global labels to each factor. All suggestions for the labels were written on the chalk board in Arabic. This took approximately 45 minutes. The group then took a 15 minute break. After the break, the group went through each factor, decided on the best global label in Arabic and did a transliteration into English. After completing all factors, the group went back through all 
factors and decided upon the cultural interpretation of each set of values. The second author then made a verbal summary of the interpretation, recorded it into a cassette recorder as the group listened and gave their consent to the message that was recorded. This took two hours. The second focus group, chaired by the second author, reviewed the values list, confirmed the labels given, made a change in the label given to one factor (Factor VI), and then made final decisions regarding the allocation of factors into the broad categories of collectivism and individualism.

\section{RESULTS}

After factor analysing the ratings, the first 15 eigenvalues were: 59.6, 13.1, 7.3, 6.3, 5.6, 4.3, 3.8, 3.4, 3.2, 3.0, 3.0, 2.9, 2.8, 2.7, 2.6. Thus a six-factor solution seemed acceptable which also met the criterion suggested by Fürntratt (1969). Factor I explained $18.2 \%$, Factor II 4.0\%, Factor III 2.2\%, Factor IV 1.9\%, Factor V 1.7\% and Factor VI $1.3 \%$ of the variance, the first six factors together explaining a total of $29.4 \%$ of the variance.

Table 1 gives the factor loadings and the communalities for the items with their highest loadings on the six factors ${ }^{1}$.

The first factor, "Nobility and Compassion", was interpreted by the focus group as referring to the ideals of a collectivist culture where family members are important but even people beyond the family are considered important and treated as equals. In this kind of society, there is a sense of social responsibility based on a general humanitarian philosophy, which is reinforced by the religion, but even people who are not religious still uphold this social responsibility. The general principle is that the privileged help the nonprivileged. Alternative labels for this factor, generated by the focus group were "cooperation", "merciful" and "sensitive to others".

Factor II was named "Discipline" by the focus group. Other names that were suggested were "the ideal person", "self-regulation", "idealism" and "perfectionism". The focus group emphasized that an individual's discipline would promote discipline in society, leading to justice and equality, an organized society and national development.

Factor III, "Advancement", was also described as "accomplishment", "growth" and "prosperity". It was agreed that people value advancement as it facilitates change for the better and this leads to a more predictable life. The focus group also agreed that advancement would bring more international respect to Egyptian citizens who currently feel the potential for growth, but also feel it is blocked by political-social and economic events.

Factor IV was labeled "Self-Actualization". Other descriptors used were "quality of life", "satisfaction" and "fulfillment". It was agreed that there are different means for different people to gain happiness. It was pointed out that money leads to independence and that this of course conflicts with the societal value of collectivism, but there was debate on this issue. It was felt that when people achieve their personal goals, this also promotes the welfare of the society as a whole.

\footnotetext{
${ }^{1}$ The full table of the factor loadings is obtainable from the authors upon request.
} 
Table 1. Factor loadings of Arabic nouns describing human values

\begin{tabular}{|c|c|c|c|c|c|c|c|}
\hline & $\begin{array}{c}\text { I. } \\
\text { Nobility \& } \\
\text { Compassion }\end{array}$ & $\begin{array}{c}\text { II. } \\
\text { Discipline }\end{array}$ & $\begin{array}{c}\text { III. } \\
\text { Advancement }\end{array}$ & $\begin{array}{c}\text { IV. } \\
\text { Self- } \\
\text { Actualization }\end{array}$ & $\begin{array}{c}\text { V. } \\
\text { Belief \& } \\
\text { Committment }\end{array}$ & $\begin{array}{l}\text { VI. } \\
\text { Counter- } \\
\text { Culture }\end{array}$ & $\mathrm{h}^{2}$ \\
\hline to become interconnected & 0.56 & & & & & & 0.49 \\
\hline granting, giving & 0.56 & & & & & & 0.41 \\
\hline greeting, welcoming & 0.52 & & & & & & 0.39 \\
\hline apology & 0.51 & & & & & & 0.35 \\
\hline connection & 0.51 & & & & & & 0.36 \\
\hline hospitality & 0.50 & & & & & & 0.34 \\
\hline agreement, understanding & 0.49 & & & & & & 0.32 \\
\hline charity & 0.49 & & & & & & 0.33 \\
\hline politeness & 0.48 & & & & & & 0.34 \\
\hline regret, sorrow & 0.48 & & & & & & 0.30 \\
\hline sensitivity & 0.47 & & & & & & 0.31 \\
\hline to pity & 0.47 & & & & & & 0.28 \\
\hline contribution, donation & 0.47 & & & & & & 0.33 \\
\hline to ask permission & 0.46 & & & & & & 0.31 \\
\hline confession & 0.45 & & & & & & 0.30 \\
\hline \multicolumn{8}{|l|}{ and 59 others } \\
\hline order, discipline & & 0.58 & & & & & 0.45 \\
\hline patience & & 0.56 & & & & & 0.41 \\
\hline accuracy & & 0.54 & & & & & 0.43 \\
\hline self control & & 0.53 & & & & & 0.38 \\
\hline good heartedness & & 0.50 & & & & & 0.47 \\
\hline punctuality & & 0.50 & & & & & 0.34 \\
\hline precision & & 0.49 & & & & & 0.41 \\
\hline tranquility & & 0.48 & & & & & 0.44 \\
\hline courtesy, politeness & & 0.48 & & & & & 0.44 \\
\hline balance, equilibrium & & 0.47 & & & & & 0.38 \\
\hline faithfulness, fidelity & & 0.46 & & & & & 0.36 \\
\hline satisfaction, contentment & & 0.46 & & & & & 0.42 \\
\hline forgiveness & & 0.46 & & & & & 0.44 \\
\hline sedateness & & 0.45 & & & & & 0.34 \\
\hline safety, security & & 0.45 & & & & & 0.45 \\
\hline \multicolumn{8}{|l|}{ and 47 others } \\
\hline discovery & & & 0.59 & & & & 0.38 \\
\hline exploration & & & 0.53 & & & & 0.41 \\
\hline $\begin{array}{l}\text { achievement, } \\
\text { accomplishment }\end{array}$ & & & 0.52 & & & & 0.40 \\
\hline fortification, strengthening & & & 0.52 & & & & 0.41 \\
\hline creation, innovation & & & 0.52 & & & & 0.30 \\
\hline knowledge & & & 0.51 & & & & 0.32 \\
\hline construction, forming & & & 0.49 & & & & 0.39 \\
\hline
\end{tabular}


Table 1. Factor loadings of Arabic nouns describing human values (continued)

\begin{tabular}{|c|c|c|c|c|c|c|c|}
\hline & $\begin{array}{c}\text { I. } \\
\text { Nobility \& } \\
\text { Compassion }\end{array}$ & $\begin{array}{c}\text { II. } \\
\text { Discipline }\end{array}$ & $\begin{array}{c}\text { III. } \\
\text { Advancement }\end{array}$ & $\begin{array}{c}\text { IV. } \\
\text { Self- } \\
\text { Actualization }\end{array}$ & $\begin{array}{c}\text { V. } \\
\text { Belief \& } \\
\text { Committment }\end{array}$ & $\begin{array}{c}\text { VI. } \\
\text { Counter- } \\
\text { Culture }\end{array}$ & $\mathrm{h}^{2}$ \\
\hline strategy & & & 0.49 & & & & 0.26 \\
\hline perfection & & & 0.48 & & & & 0.30 \\
\hline study, research & & & 0.47 & & & & 0.29 \\
\hline aiming at & & & 0.45 & & & & 0.28 \\
\hline learning & & & 0.45 & & & & 0.40 \\
\hline exactness & & & 0.44 & & & & 0.31 \\
\hline renewal, modernization & & & 0.43 & & & & 0.31 \\
\hline progression, advancement & & & 0.43 & & & & 0.38 \\
\hline \multicolumn{8}{|l|}{ and 42 others } \\
\hline freedom of choice & & & & 0.50 & & & 0.40 \\
\hline luxury & & & & 0.49 & & & 0.34 \\
\hline delight, happiness & & & & 0.49 & & & 0.43 \\
\hline wealth & & & & 0.49 & & & 0.36 \\
\hline amusement, entertainment & & & & 0.48 & & & 0.32 \\
\hline personal liberty & & & & 0.48 & & & 0.30 \\
\hline beauty, grace (fullness) & & & & 0.47 & & & 0.32 \\
\hline love, passion & & & & 0.47 & & & 0.36 \\
\hline happiness, well being & & & & 0.46 & & & 0.34 \\
\hline peace of mind & & & & 0.45 & & & 0.35 \\
\hline blessing & & & & 0.43 & & & 0.41 \\
\hline riches & & & & 0.42 & & & 0.32 \\
\hline companionship & & & & 0.42 & & & 0.35 \\
\hline joking & & & & 0.41 & & & 0.22 \\
\hline shapeliness & & & & 0.41 & & & 0.25 \\
\hline \multicolumn{8}{|l|}{ and 27 others } \\
\hline veil & & & & & 0.61 & & 0.37 \\
\hline $\begin{array}{l}\text { religious duty, religious } \\
\text { obligation }\end{array}$ & & & & & 0.61 & & 0.44 \\
\hline to go on pilgrimage & & & & & 0.60 & & 0.41 \\
\hline Arabism, Arab nationalism & & & & & 0.57 & & 0.42 \\
\hline fasting & & & & & 0.57 & & 0.44 \\
\hline $\begin{array}{l}\text { struggle, holy war (jihad) } \\
\text { for Muslims }\end{array}$ & & & & & 0.56 & & 0.40 \\
\hline fear of God & & & & & 0.53 & & 0.48 \\
\hline prayer & & & & & 0.53 & & 0.45 \\
\hline nationalism & & & & & 0.52 & & 0.40 \\
\hline national defense & & & & & 0.52 & & 0.41 \\
\hline prayer, invocation (of God) & & & & & 0.51 & & 0.37 \\
\hline patriotism & & & & & 0.49 & & 0.38 \\
\hline
\end{tabular}


Table 1. Factor loadings of Arabic nouns describing human values (continued)

\begin{tabular}{|c|c|c|c|c|c|c|c|}
\hline & $\begin{array}{c}\text { I. } \\
\text { Nobility \& } \\
\text { Compassion }\end{array}$ & $\begin{array}{c}\text { II. } \\
\text { Discipline }\end{array}$ & $\begin{array}{c}\text { III. } \\
\text { Advancement }\end{array}$ & $\begin{array}{c}\text { IV. } \\
\text { Self- } \\
\text { Actualization }\end{array}$ & $\begin{array}{c}\text { V. } \\
\text { Belief \& } \\
\text { Committment }\end{array}$ & $\begin{array}{c}\text { VI. } \\
\text { Counter- } \\
\text { Culture }\end{array}$ & $\mathrm{h}^{2}$ \\
\hline kinship & & & & & 0.47 & & 0.45 \\
\hline Arab unity & & & & & 0.47 & & 0.28 \\
\hline martyrdom & & & & & 0.46 & & 0.33 \\
\hline \multicolumn{8}{|l|}{ and 23 others } \\
\hline arrogance & & & & & & 0.62 & 0.45 \\
\hline dispersal, scattering & & & & & & 0.60 & 0.42 \\
\hline insult, indignity & & & & & & 0.59 & 0.41 \\
\hline to lie, to deceive & & & & & & 0.56 & 0.37 \\
\hline enmity, hostility & & & & & & 0.56 & 0.37 \\
\hline anarchy & & & & & & 0.54 & 0.36 \\
\hline to spy & & & & & & 0.53 & 0.33 \\
\hline fanaticism, intolerance & & & & & & 0.53 & 0.34 \\
\hline attack, aggression, assault & & & & & & 0.53 & 0.30 \\
\hline enslavement & & & & & & 0.52 & 0.30 \\
\hline revenge & & & & & & 0.52 & 0.35 \\
\hline dirtiness, filthiness & & & & & & 0.51 & 0.30 \\
\hline humiliation & & & & & & 0.51 & 0.28 \\
\hline sectarianism & & & & & & 0.50 & 0.28 \\
\hline war & & & & & & 0.50 & 0.33 \\
\hline and 39 others & & & & & & & \\
\hline
\end{tabular}

* Note.

Only factor loadings $\geq .30$ are shown.

Factor V "Belief and Commitment" was also named "faith", "pious" and "loyalty". The group felt that these issues are inbuilt into their culture and religion, and exist in the "collective unconscious" and in the "psyche". The focus group noted that this factor emphasizes a strong belief in the metaphysical and a belief in fate. It was noted that this was the most religious factor of all, but that people who do not actively practice religion still basically believe in the values listed. The group refused to label this factor "religion and nationalism" when this was suggested by the second author near the end of the discussion. The group stated that the list of values in this factor reflected the "content" of a belief system and that all people have a belief system through which they set goals and make a commitment to work towards these goals. For example, the factor included "Kin" and this reflects a belief system that relates to humanitarian beliefs.

For Factor VI the focus group suggested "injustice and cruelty" as a label. Suggestions were also made to label this "intimidation", "totalitarian", "harm" and "meanness". From these possibilities, and after much discussion with Arab-speaking academics and members of the second focus group, the authors decided to use "counter 
Table 2. Descriptive statistics of the items loading highest on the Egyptian value dimensions $(a>.45)$

\begin{tabular}{lcccc}
\hline & Minimum & Maximum & Mean & Std. Deviation \\
\hline I. Nobility \& Compassion & -1.00 & 5.00 & 3.67 & 0.94 \\
II. Discipline & -0.63 & 5.00 & 4.09 & 0.89 \\
III. Advancement & -0.73 & 5.00 & 3.37 & 1.08 \\
IV. Self-Actualization & -2.00 & 5.00 & 3.83 & 0.97 \\
V. Belief \& Committment & -1.67 & 5.00 & 3.73 & 1.18 \\
VI. Counter-Culture & -5.00 & 4.41 & -1.60 & 1.89 \\
\hline
\end{tabular}

culture" as the values listed in this factor do not fit with either traditional or contemporary value systems of Egyptians. With regard to the concepts comprised by this factor the focus group felt that these values would be upheld by two groups of people. Firstly, they felt some people were innately "mean" and had a philosophy that the ends justify the means. Secondly, they felt that the values listed in this factor were a reaction to injustice and flaws in an existing social-political system that fails to punish wrong-doers and ensure the rights of others, thereby leaving people to fend for themselves by adopting the values of the wrong-doers in order to survive.

In order to give an estimate about the degree to which each of the value dimensions was advocated or disregarded by the participants we selected the items loading on each factor with a $>.45$ and computed the ranges, means and standard deviations of their ratings. These results are shown in Table 2 .

It can be seen that value concepts pertaining to Factor II (Discipline) as well as those loading highest on Factor IV (Self-Actualization) and V (Belief and Commitment) were rated highest, whereas those of Factor VI (Counter-Culture) received the lowest ratings.

Table 3 gives the partial correlations between the factor scores and the scale means on the SVS.

It can be seen from Table 3 that correlations between the Egyptian value dimensions and the SVS scales are low to moderate. Nobility and Compassion has a low but significant correlation with Conformity and a negative one with Self-Enhancement from the SVS and Discipline aligns negatively with Power. Advancement correlates substantially and positively with Self-Enhancement and Achievement and correlates negatively with Tradition. Belief and Commitment correlates positively with Tradition and Security and negatively with Self-Enhancement. Counter-Culture has a small but significant positive correlation with Power and negative ones with Conformity and Benevolence.

The Pearson correlation of the factor scores from the value dimensions and the Big Five factors of personality, as measured by the NEO-FFI in a subsample of 43 participants, are shown in Table 4.

Advancement is correlated positively and significantly with Openness to Experience and Self-Actualization aligns with Conscientiousness; Counter-Culture correlates 
Table 3. Partial correlations between the factor scores of the value dimensions and the SVS scales with the SVS total score controlled for

\begin{tabular}{lcccccc}
\hline & $\begin{array}{c}\text { I. } \\
\text { Nobility \& } \\
\text { Compassion }\end{array}$ & $\begin{array}{c}\text { II. } \\
\text { Discipline }\end{array}$ & $\begin{array}{c}\text { III. } \\
\text { Advancement }\end{array}$ & $\begin{array}{c}\text { IV. } \\
\text { Self- } \\
\text { Actualization }\end{array}$ & $\begin{array}{c}\text { V. } \\
\text { Belief \& } \\
\text { Committment }\end{array}$ & $\begin{array}{c}\text { VI. } \\
\text { Counter- } \\
\text { Culture }\end{array}$ \\
\hline Conformity & $0.33^{*}$ & 0.23 & -0.06 & -0.27 & -0.03 & $-0.52^{* *}$ \\
Tradition & 0.24 & 0.10 & $-0.38^{*}$ & $-0.37^{*}$ & $0.42^{* *}$ & 0.04 \\
Benevolence & 0.27 & 0.24 & -0.25 & -0.24 & -0.10 & $-0.34^{*}$ \\
Universalism & 0.02 & 0.09 & 0.30 & -0.08 & -0.27 & 0.10 \\
Self-Enhancement & $-0.35^{*}$ & 0.05 & $0.64 * *$ & 0.26 & $-0.40^{*}$ & 0.03 \\
Stimulation & -0.14 & -0.28 & -0.02 & $0.37 *$ & -0.11 & 0.22 \\
Hedonism & -0.18 & -0.15 & -0.10 & $0.49^{* *}$ & -0.17 & 0.15 \\
Achievement & -0.14 & 0.18 & $0.46^{* *}$ & -0.04 & -0.26 & -0.02 \\
Power & -0.24 & $-0.41^{* *}$ & -0.12 & -0.00 & 0.26 & $0.32^{*}$ \\
Security & 0.26 & -0.10 & -0.21 & $-0.35^{*}$ & $0.46^{* *}$ & -0.06 \\
\hline
\end{tabular}

$* p<.05, * * p<.01$

Table 4. Pearson correlations between the factor scores of the value dimensions and the Big Five factors of personality

\begin{tabular}{lccccc}
\hline & $\mathrm{N}$ & $\mathrm{E}$ & $\mathrm{O}$ & $\mathrm{A}$ & $\mathrm{C}$ \\
\hline I. Nobility \& Compassion & 0.15 & 0.10 & -0.13 & 0.23 & 0.19 \\
II. Discipline & -0.19 & 0.12 & -0.08 & 0.09 & 0.24 \\
III. Advancement & -0.20 & 0.19 & $0.47^{* *}$ & -0.02 & 0.28 \\
IV. Self-Actualization & -0.15 & 0.27 & 0.06 & -0.03 & $0.32^{*}$ \\
V. Belief \& Commitment & 0.10 & 0.01 & -0.07 & -0.29 & -0.16 \\
VI. Counter-Culture & 0.02 & -0.01 & -0.03 & $-0.42^{* *}$ & -0.19 \\
\hline
\end{tabular}

$\mathrm{N}=$ Neuroticism, $\mathrm{E}=$ Extraversion, $\mathrm{O}=$ Openness to Experience, $\mathrm{A}=$ Agreeableness, $\mathrm{C}=$ Conscientiousness $* p<.05, * * p<.01$

negatively and significantly with Agreeableness. All the other correlations do not differ significantly from zero.

\section{DISCUSSION}

Factor I (Nobility and Compassion) and Factor III (Advancement) both reflect collectivist values that would lead to a better life for all. The values comprised by Factor IV (Self-Actualization) and Factor VI (Counter Culture) reflect individualist goals. Factor 
II (Discipline) and Factor V (Belief and Commitment) reflect values that can be described as both indiviualist and collectivist in that they represent the "ideal" both for an individual and for the culture. Thus, the dimensions found support Hofstede's $(1984,1994)$ position, as he considered Arabic society to be "moderately collectivistic".

Factor V (Belief and Commitment) expresses culturally specific ideals of the Arab society. Both religious and political issues appeared in this factor. This finding is in line with the important role religion plays in Arab society as well as with the fact that Arabic nationalism and religious issues are inter-related.

With regard to Factor VI (Counter-Culture), it is surprising to find concepts with an obviously "negative" connotation that typifies a Machiavellian kind of character. Although the mean ratings of concepts loading highest on this factor are low, 20\% of the participants had a positive score on this dimension.

In summary, confirming our expectations, the values found in Egyptian society are related to religion and community to a very high degree. They reflect the ideals of the Islamic world - with religion playing a central role in society - as well as those of collectivist societies. In this respect Egyptian values differ markedly from those found in the individualist society such as Austria, where religious ideals are pursued privately and separately from other aspects of life and values pertaining to personal harmony and materialistic gain are endorsed (Renner, 2003). Thus, not surprisingly, universal conceptions of human values like the SVS only partly account for such culturally specific ideals and should be supplemented by culturally sensitive approaches.

Keeping in mind that the sample sizes for the correlational studies were quite low, these results should be interpreted with extreme caution. It appears that the Egyptian value dimensions only partly represent the universal ones suggested by Schwartz (1992). The correlations between the Egyptian value dimensions and the NEO-FFI are low, suggesting that the value dimensions are distinct from personality traits. On the other hand, all significant correlations between the Egyptian value dimensions and the SVS can be easily interpreted. For example, it can be easily understood that people who endorse Counter-Culture tend to score high on Power and low on Conformity and Benevolence in the Schwartz Value Survey and that Belief and Commitment aligns with high scores on Tradition and Security and low ones on Self-Enhancement. The present correlational results are exploratory by their nature, however, and should stimulate further research addressing issues of convergent and differential validity of the Egyptian value dimensions and aiming at a replication of our findings using larger, more representative samples of Egyptian society. Further comparisons between Egypt and other Arabic nations should also be done to demonstrate possible cultural differences and similarities.

\section{REFERENCES}

Aavik, T., \& Allik, J. 2002. The structure of Estonian personal values: a lexical approach. European Journal of Personality, 16, 221-235.

Abdalla, I. A. 1996. Attitudes toward women in the Arabian Gulf region. Woman in Management Review, 11, 29-39. 
Al Hashimi, A. H. 1981. On islamizing the discipline of psychology. In I. R. Al-Faruqi \& A. O. Nasseef (eds.), Social and natural sciences: The Islamic perspective (pp. 49-70). Sevenoaks: Hodder and Stoughton.

Ali, A. 1986. The Arab executive: A study in values and work orientation. American-Arab Affairs, 19, 94-100. Ali, A. 1987. We fumble and stumble in the modern world. Arabia, 7, 53-55.

Ali, A., \& Al-Shakis, M. 1985. Managerial value systems for working in Saudi Arabia: An empirical investigation. Group \& Organizational Studies, 10, 135-151.

Ali, A., \& Al-Shakis, M. 1989. Managerial beliefs about work in two Arab states. Organization Studies, 10, $169-186$.

Almaney, A. J. 1981. Cultural traits of the Arabs: Growing interest for international management. Management International Review, 21, 10-18.

Baalbaki, R. 2001. Al-Mawrid. A modern Arabic-English Dictionary. Beirut: Dar El-Ilm Lilmalayin.

Barakat, H. 1974. Socioeconomic, cultural and personality forces determining development in Arab society. Social Praxis, 2, 179-204.

Buchanan, E. A. 1997. Cultural heritage, social values, and information in the Arab world. Journal of Education for Library and Information Science, 38, 215-220.

Cattell, R. B. 1966. The scree test for the number of factors. Multivariate Behavioral Research, 1, $245-276$.

Cawley, M. J., Martin, J. E., \& Johnson, J. A. 2000. A virtues approach to personality. Personality and Individual Differences, 28, 997-1013.

Costa, P. T., Jr., \& McCrae, R. R. 1992. Revised NEO Personality Inventory (NEO PI-R) and NEO FiveFactor Inventory (NEO-FFI) professional manual. Odessa, FL: Psychological Assessment Resources.

De Fruyt, F., \& Furnham, A. 2000. Advances in the assessment of the five factor model. Psychologica Belgica, 40, 51-75.

Fürntratt, E. 1969. Zur Bestimmung der Anzahl interpretierbarer gemeinsamer Faktoren in Faktorenanalysen psychologischer Daten [Determining the number of interpretable common factors in factor analyses of psychological data]. Diagnostica, 15, 62-75.

Guadagnoli, E., \& Velicer, W. F. 1988. Relation of sample size to the stability of component patterns. Psychological Bulletin, 103, 265-275.

Haddad, Y. 1984. Islam, women and revolution in twentieth-century Arab thought. The Muslim World, 74, 137-160.

Hajazi, M. 1979. Toward strategic cultural development in the Arab nation. The Arab Future, 10, 6-24.

Harris, P. R., \& Moran, R. T. 2000. Managing cultural differences (5th ed.). Houston: Gulf.

Hattar-Pollara, M., Meleis, A. I., \& Nagib, H. 2000. A study of the spousal role of Egyptian woman in clerical jobs. Health Care for Women International, 21, 305-317.

Hofstede, G. 1984. Culture's consequences. International differences in work-related values. Newbury Park: Sage.

Hofstede, G. 1994. Cultures and Organizations. Intercultural cooperation and its importance for survival. London: Harper Collins.

Hopkins, N. S., \& Ibrahim, S. E. 1997. Arab Society: Class, gender, power, and development. Cairo: The American University in Cairo Press.

Joseph, J. E. 1991. Language as a cultural commodity. Polylingua, 1, 175-185.

Moracco, J. 1983. Some correlates of the Arab character. Psychology. A Quarterly Journal of Human Behavior, 20, 47-54.

Patai, R. 1973. The Arab mind. New York: Charles Scribner's Sons.

Renner, W. 2003. Human values: a lexical perspective. Personality and Individual Differences, 34, $127-141$.

Renner, W., Peltzer, K., \& Phaswana, M. G. 2003. The structure of values among Northern Sotho speaking people in South Africa. South African Journal of Psychology, 33, 103-108.

Saucier, G. 2000. Isms and the structure of social attitudes. Journal of Personality and Social Psychology, 78, 323-331.

Scholl-Schaaf, M. 1975. Werthaltung und Wertsystem. Ein Plädoyer für die Verwendung des Wertkonzeptes in der Sozialpsychologie [Value orientation and value system. A plea for using the value concept in social psychology]. Bonn: Bouvier.

Schwartz, S. H. 1992. Universals in the content and structure of values: theoretical advances and empirical tests in 20 countries. Advances in Experimental Social Psychology, 25, 1-65. 
Schwartz, S. H. 1994. Are there universal aspects in the structure and contents of human values? Journal of Social Issues, 50, 19-45.

Schwartz, S. H., \& Bardi, A. 2001. Value hierarchies across cultures. Taking a similarities perspective. Journal of Cross-Cultural Psychology, 32, 268-290.

Sidani, Y. M., \& Gardner, W. L. 2000. Work values among Lebenese workers. The Journal of Social Psychology, 140, 597-607.

Thomas, K. 2000. The new Arab women. The Middle East, 27, 43-45.

Triandis, H. C. 1994. Culture and social behavior. New York, NY: McGraw Hill.

Triandis, H. C. 1995. Individualism and collectivism. Boulder, CO: Westview Press.

(Manuscript received June 7, 2005; Revision accepted May 2, 2006) 